\title{
Lipídeos na Alimentação de Alevinos Revertidos de Tilápia do Nilo (Oreochromis niloticus, L.) \\ Fábio Meurer ${ }^{1}$, Carmino Hayashi ${ }^{2}$, Wilson Rogério Boscolo ${ }^{3}$, Claudemir Martins Soares ${ }^{4}$
}

\begin{abstract}
RESUMO - Objetivando avaliar os efeitos de níveis crescentes de lipídeos na ração sobre desempenho, velocidade de trânsito do alimento, consumo de ração e gordura corporal, foram utilizados 168 alevinos de tilápia do Nilo, revertidos, com peso médio de $1,24 \pm$ $0,03 \mathrm{~g}$ e comprimento médio de 4,10 $\pm 0,30 \mathrm{~cm}$, distribuídos em 24 aquários, de $50 \mathrm{~L}$ de volume útil, em um delineamento inteiramente casualizado com seis tratamentos e quatro repetições, considerando-se um aquário com sete animais como unidade experimental, por um período de 40 dias. A temperatura foi mantida em $27,2 \pm 0,6^{\circ} \mathrm{C}$ por aquecedores de $100 \mathrm{~W}$ com termostato e aeração constante. As rações foram formuladas sendo isoprotéicas, isoenergéticas e isoaminoacídicas para lisina e metionina mais cistina, variando quanto ao nível de lipídeos $(3,0 ; 4,8 ; 6,6 ; 8,4 ; 10 ; 2 ;$ e 12,0\%). Foram avaliados o efeito do nível de lipídeos sobre as médias do ganho de peso (GP), conversão alimentar (CA), taxa de eficiência protéica (TE), consumo de ração (CR), velocidade de passagem de alimento (VP) e gordura corporal (GC). O GP, TE, CA diminuíram linearmente com o aumento do nível de lipídeos na ração, enquanto que a GC aumentou, o CR não apresentou diferença entre os tratamentos; a VP apresentou um comportamento quadrático com ponto de mínimo em $6,0 \%$ de gordura na ração. Como conclusão recomenda-se o uso de 3,0\% de lipídeos na ração de alevinos de tilápia do Nilo e ressalta-se a melhor utilização do amido como fonte de energia em relação à gordura para esta espécie.
\end{abstract}

Palavras-chave: alevinos, amido, gordura, nutrição, Oreochromis niloticus e tilápia do Nilo

\section{Fat on the Reverted Nile Tilapia (Oreochromis niloticus) Fingerlings Feeding}

\begin{abstract}
Aiming to evaluate the effect of increasing levels of fat in the ration on performance, speed of food pass, consummates of ration and corporal fat, it were used 168 Nile tilapia fingerlings, reverted, with average weight of $1.24 \pm 0,03 \mathrm{~g}$ and average size of $4.10 \pm 0.30 \mathrm{~cm}$, allotted to 24 aquariums, of $50 \mathrm{~L}$ of useful volume, in a completely randomized design with six treatments and four replicates, where the aquarium with seven animals was considered experimental unit, for a period of 40 days. The temperature was kept in $27.2 \pm 0.6^{\circ} \mathrm{C}$ for heaters of $100 \mathrm{~W}$ with thermostat and constant aeration. Diets were formulated to be isonitrogen, isoenergy and isoamino acidic for lysine and cystine + methionine, varying how much to the level of fat $(3.0,4.8,6.6,8.4,10.2$, and $12.0 \%)$. They had been evaluated the effect of the level of fat on the averages of the weight gain (GP), feed conversion (CA), tax of protein efficiency (TE), consumption of ration (CR), speed of food pass (VP) and corporal fat (GC). The GP, TE, CA had decreased linearly as the dietary level of fat increased, while GC increased, the CR did not present difference between the treatments, the VP presented a quadratic effect with point of minimum in $6.0 \%$ of fat in the ration. To reverted Nile tilapia fingerlings it is recommend $3.0 \%$ as fat level in the diet and was show a better starch utilization like energy source than fat in this specie.
\end{abstract}

Key Words: fat, fingerlings, Nile tilapia, nutrition, Oreochromis niloticus, starch

\section{Introdução}

A tilápia do Nilo (Oreochromis niloticus) é uma espécie de peixe bastante versátil na piscicultura, pois adapta-se tanto ao cultivo extensivo sem qualquer tecnologia empregada, quanto ao sistema de criação em tanques-rede com rações completas com alta tecnologia de produção. Além do que é apreciada em "pesque-pagues" e pela indústria de filetagem, graças às qualidades organolépticas e à inexistência de espinhos em "Y" no seu filé.
A gordura é considerada como a principal forma de armazenagem de energia corporal, dadas as suas características de hidrofobicidade, a facilidade do acondicionamento das moléculas de triacilgliceróis no interior dos adipócitos e a quantidade de energia fornecida pela mesma em relação ao carboidrato e a proteína; no entanto, ela participa em diversas outras funções no organismo, como por exemplo na constituição da parede celular, formação dos hormônios esteróides, produção de mensageiros intra e extra-celulares (os eicosanóides), entre outras (Lehninger et al., 1995).

\footnotetext{
${ }^{1}$ Zootecnista Msc., Pós-Graduando do Programa de Pós-Graduação em Zootecnia, Departamento de Zootecnia/Universidade Estadual de Maringá. Laboratório de Aqüicultura, Depto de Biologia/UEM, Av. Colombo, n 5790, CEP 87020-900, Jd. Universitário Maringá - Paraná. E.mail: f-meurer@bol.com.br

2 Professor Titular do Depto de Biologia/UEM. E.mail: chayashi@uem.br

${ }^{3}$ Zootecnista Msc., Prof. do curso de Engenharia de Pesca/UNIOESTE, Pós-Graduando do PPZ/UEM.

${ }^{4}$ Técnico de Nível Superior - Biólogo, Laboratório de Aqüicultura, DBI/UEM.
} 
Os lipídeos são uma importante fonte de energia que pode ser utilizada na alimentação dos peixes (Wilson, 1998), pois é uma fonte de alimento facilmente encontrada no mercado e fornece, além da energia, uma quantidade considerável de ácidos graxos essenciais (Steffens, 1987). A utilização de lipídeos como fonte de energia varia conforme a espécie de peixe, dependendo de seu hábito alimentar, sendo que geralmente rações para peixes carnívoros podem ter níveis mais elevados de lipídeos que aquelas para onívoros e herbívoros (Wilson, 1998). El-Dahhar \& El-Shazly (1993) afirmaram que a tilápia não utiliza eficientemente o lipídio como fonte de energia. Chou \& Shiau (1996) destacam que a tilápia não utiliza a energia suplementar proveniente do lipídeo (acima de $5 \%$ na ração), para o crescimento. Wilson (1998), indica de 5 a 10\% de inclusão de lipídeos para peixes de clima quente. Chou \& Shiau (1996), encontraram o valor de $12 \%$ de lipídeos na ração como nível de melhor ganho de peso para tilápias híbridas juvenis. Lovell (1989), afirma que as tilápias não toleram níveis tão altos de gordura quanto aos salmonídeos.

A fonte de lipídeos utilizada na ração pode influenciar significativamente no crescimento e conversão alimentar dos peixes, segundo Stickney \& McGeachin (1983). Wilson (1995) afirma que os óleos de origem vegetal são boas fontes de energia para peixes de clima tropical. Hayashi et al. (2000) concluíram que os óleos de soja, canola, girassol, linhaça, arroz e milho proporcionaram desempenho equivalente $(\mathrm{P}>0,05)$ para alevinos de tilápia do Nilo.

A inclusão de lipídeos na ração dos peixes leva a um aumento do nível de gordura corporal, sendo que este aumento está relacionado com o nível de inclusão, isto é, quanto maior o nível de lipídeo dietário maior o depósito de gordura no peixe (Cyrino, 1995).

O presente trabalho foi conduzido com o objetivo de determinar o melhor nível de lipídeos em rações para alevinos de tilápia do Nilo, revertidos, na fase inicial, tomando por base os resultados de desempenho e porcentagem de gordura corporal, assim como avaliar as implicações dos níveis de lipídeos no consumo de ração e velocidade de trânsito alimentar dos mesmos.

\section{Material e Métodos}

O experimento foi realizado no Laboratório de Aquicultura, Departamento de Biologia Universidade Estadual de Maringá, no período de 23 de fevereiro a 02 de abril de 1999. Foram utilizados 168 alevinos de tilápia do Nilo (Oreochromis niloticus), revertidos sexualmente com uso de hormônio masculinizante 17-a-metil- testosterona na ração utilizada na fase larval, com peso médio inicial de 1,24 $\pm 0,03 \mathrm{~g}$ e comprimento médio inicial de 4,10 $\pm 0,30 \mathrm{~cm}$. Os alevinos foram distribuídos em um delineamento inteiramente casualizado com seis tratamentos e quatro repetições, sendo a unidade experimental constituída por um aquário com capacidade para $50 \mathrm{~L}$ com sete animais. Os aquários possuíam aeração constante por meio de pedra microporosa ligada a um compressor de ar e a temperatura foi mantida com o uso de aquecedores de 100 watts com termostatos.

As rações foram formuladas de acordo com as exigências nutricionais da espécie (NRC, 1993), à base de farelo de soja, milho, farinha de peixe e óleo de soja como fonte de gordura, sendo as mesmas isocalóricas, isoprotéicas, isoaminoacídicas para lisina e metionina+cistina, isocálcicas, diferindo quanto ao nível de óleo $(3,0 ; 4,8 ; 6,6 ; 8,4 ; 10,2 ;$ e $12,0 \%$ da ração), conforme Tabela 1 .

Para a confecção das rações os ingredientes foram moídos em um moinho de faca com peneira 0,5 mm (Hayashi et al., 1999a), e misturados de maneira a se apresentar uma mistura homogênea. A peletização das rações foi efetuada com o umedecimento das mesmas com água a uma temperatura de cerca de $50^{\circ} \mathrm{C}$ e então processadas em um moinho e secas em estufa de ventilação forçada por cerca de 12 horas.

Os peletes foram desintegrados e separados em diferentes diâmetros com o uso de peneiras de diversas malhas, para apresentarem tamanho adequado ao tamanho da boca dos animais e adequados conforme os mesmos cresciam.

Os peixes foram alimentados três vezes ao dia, as $8 \mathrm{~h}, 13 \mathrm{~h} 30$ e $17 \mathrm{~h}$. A quantidade diária de ração fornecida aos animais foi de $10,0 \%$ do peso vivo, sendo que esta quantidade foi corrigida semanalmente através da pesagem de todos os indivíduos de cada unidade experimental.

Os aquários foram sifonados duas vezes ao dia para a retirada das fezes e troca da água (cerca de $20 \%$ do volume de água contida no aquário, em cada sifonagem). Semanalmente foi feita a medida dos parâmetros físico-químicos da água, condutividade elétrica, oxigênio dissolvido e $\mathrm{pH}$. A temperatura da água dos aquários foi medida duas vezes ao dia, sendo pela manhã (8h30) e à tarde (16h).

\section{R. Bras. Zootec., v.31, n.2, p.566-573, 2002}


Tabela 1 - Composição percentual e química das rações experimentais com diferentes níveis de lipídeos (matéria natural) ${ }^{1}$ Table 1 - Percent and chemical composition of experimental different fat level diets (fed basis) ${ }^{1}$

\begin{tabular}{|c|c|c|c|c|c|c|}
\hline \multirow[t]{2}{*}{$\begin{array}{l}\text { Ingrediente }(\%) \\
\text { Ingredient }(\%)\end{array}$} & \multicolumn{6}{|c|}{$\begin{array}{c}\text { Lipídeos na ração (\%) } \\
\text { Fat in diet }(\%)\end{array}$} \\
\hline & 3,00 & 4,80 & 6,60 & 8,40 & 10,20 & 12,00 \\
\hline Milho $^{3}$ (Corn) & 31,29 & 24,39 & 17,59 & 10,80 & 4,01 & 0,00 \\
\hline Farelo de soja ${ }^{3}$ (Soybean meal) & 57,44 & 58,81 & 60,13 & 61,45 & 62,77 & 63,54 \\
\hline Farinha peixe $^{3}\left(\right.$ Fish meal $\left.^{3}\right)$ & 5,00 & 5,00 & 5,00 & 5,00 & 5,00 & 5,00 \\
\hline Bagaço de cana (Sugarcane bagasse) & 0,00 & 5,94 & 8,31 & 8,44 & 8,57 & 7,86 \\
\hline Inerte (areia) (Inert) & 0,00 & 0,00 & 1,10 & 4,44 & 7,77 & 9,80 \\
\hline Óleo de soja ${ }^{3}$ (Soybean oil) & 1,15 & 3,19 & 5,20 & 7,21 & 9,22 & 11,15 \\
\hline Celulose (Cellulose) & 2,44 & 0,00 & 0,00 & 0,00 & 0,00 & 0,00 \\
\hline Calcário (Limestone) & 0,22 & 0,16 & 0,11 & 0,07 & 0,02 & 0,00 \\
\hline Fosfato bicálcico (Dicalcium phosphate) & 1,31 & 1,39 & 1,45 & 1,51 & 1,57 & 1,60 \\
\hline $\mathrm{L}$-lisina $\mathrm{HCl}($ L-lysine $\mathrm{HCl})$ & 0,13 & 0,10 & 0,07 & 0,05 & 0,02 & 0,00 \\
\hline DL- metionina 99 (DL- methionine 99) & 0,00 & 0,01 & 0,02 & 0,02 & 0,03 & 0,00 \\
\hline Suplem. min. vitam. ${ }^{2}$ (Vit. and min. premix) & 0,50 & 0,50 & 0,50 & 0,50 & 0,50 & 0,50 \\
\hline $\operatorname{Sal}($ Salt $)$ & 0,50 & 0,50 & 0,50 & 0,50 & 0,50 & 0,50 \\
\hline $\mathrm{BHT}$ & 0,02 & 0,02 & 0,02 & 0,02 & 0,02 & 0,02 \\
\hline \multicolumn{7}{|l|}{ Valores calculados } \\
\hline ED (kcal/kg) (Digestible energy) & 800,00 & 800,00 & 2800,00 & 2800,00 & 2800,00 & 2860,00 \\
\hline $\mathrm{PB}$ (Crude protein), $\%$ & 32,00 & 32,00 & 32,00 & 32,00 & 32,00 & 32,00 \\
\hline Amido $(\text { Starch })^{4}, \%$ & 26,74 & 23,13 & 19,07 & 15,01 & 10,95 & 8,57 \\
\hline Metionina+cistina (\%) (Methionine + cystine) & 1,02 & 1,02 & 1,02 & 1,02 & 1,02 & 1,02 \\
\hline Lisina (Lysine), $\%$ & 2,10 & 2,10 & 2,10 & 2,10 & 2,10 & 2,10 \\
\hline Fibra bruta (\%) (Crude fiber) & 5,98 & 6,19 & 7,00 & 7,00 & 7,00 & 6,17 \\
\hline Cálcio (Calcium), \% & 0,88 & 0,88 & 0,88 & 0,88 & 0,88 & 0,88 \\
\hline Fósforo (phosphorus), \% & 0,80 & 0,80 & 0,80 & 0,80 & 0,80 & 0,80 \\
\hline \multicolumn{7}{|c|}{ 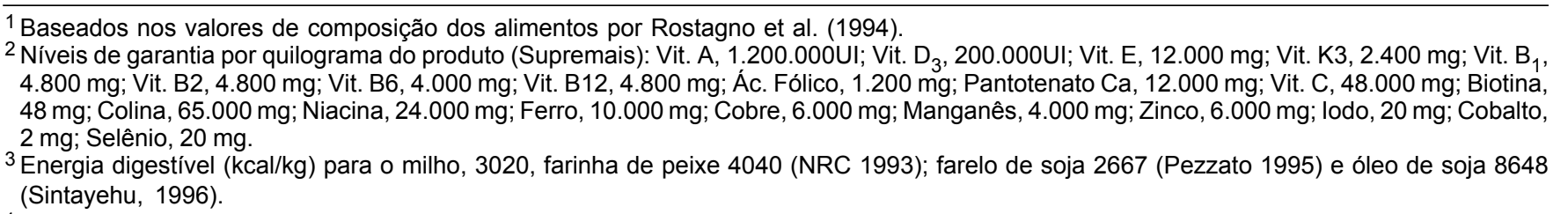 } \\
\hline
\end{tabular}

Ao final do experimento de desempenho foram tomadas as medidas de peso e comprimento total dos animais de cada unidade experimental. As variáveis avaliadas foram o ganho de peso, comprimento total, conversão alimentar, taxa de eficiência protéica, gordura corporal, velocidade de trânsito do alimento e consumo da ração. A taxa da eficiência protéica foi calculada de acordo com a expressão proposta por Jauncey \& Ross (1982).

Para avaliar a velocidade de trânsito do alimento utilizou-se de 162 animais com peso médio de 7,47 \pm 0,68 g e comprimento médio de $7,41 \pm 0,20 \mathrm{~cm}$, sendo que todos os animais de cada tratamento foram agrupados, sendo retirados os maiores e menores, para serem redistribuídos em um delineamento intei- ramente casualizado com seis tratamentos e três repetições em 18 aquários com capacidade para $50 \mathrm{~L}$.

Avaliou-se a velocidade de trânsito do alimento em horas para cada ração, utilizando-se como marcador $1,00 \%$ de óxido de cromo incorporado às rações. Para tal os peixes de cada unidade experimental foram alimentados à vontade na primeira alimentação, pela manhã, e a cada 30 minutos foi realizada a coleta das fezes, mediante sifonagem do fundo dos aquários, para verificar a proporção de fezes coradas com o marcador em relação ao total de fezes em cada intervalo, sendo realizado novo arraçoamento, até o momento em que $100 \%$ das fezes coletadas se apresentassem coradas. 
Para avaliar o efeito dos níveis de gordura na ração sobre o consumo alimentar dos peixes, foi fornecida uma quantidade de ração conhecida $(\mathrm{RC})(5,00 \mathrm{~g})$ para cada unidade experimental, sendo a mesma mantida por trinta minutos para que os peixes se alimentassem; os resíduos desta foram sifonados do aquário e passados em papel filtro de peso conhecido. Este material foi seco em estufa de ventilação forçada por $24 \mathrm{~h}$, após pesado e subtraído o peso do papel de filtro; sendo então determinado o peso da ração residual (RR). Para medir a perda por dissolução das rações para água e pelo processo de sifonagem e filtragem, foi feito, para cada ração, o mesmo procedimento anterior mas em aquários sem peixes. A diferença percentual da RC com aquela retirada do aquário foi considerada como coeficiente de dissolução da ração (CD), o qual foi utilizado para correção das perdas pelo processo.

De posse destes dados foi calculado a porcentagem de consumo alimentar em função do peso dos animais para cada ração, da seguinte maneira: a RR foi acrescentada o $\mathrm{CD}$ da ração e então subtraído do $\mathrm{RC}$, conforme a seguinte expressão: Consumo (\%PV) $=\mathrm{RC}-(\mathrm{RR}+\mathrm{CD}) / \mathrm{PL} \times 100$; onde: $\mathrm{RC}=$ Ração fornecida; $\mathrm{RR}=$ Ração residual $\mathrm{CD}=$ Coeficiente de dissolução da ração; PL = Peso do lote de peixes.

Após o término do experimento, todos os peixes foram mantidos em jejum por dois dias, e então moídos e congelados para análise da percentagem de gordura corporal total, conforme metodologia descrita por Silva (1990).

Os dados obtidos foram submetidos à análise de variância, e em caso de diferenças aplicou-se análise de regressão através do programa estatístico Sistema de Análise Estatística e Genética (SAEG) descrito por Euclydes (1983).

\section{Resultados e Discussão}

Os valores médios obtidos para os parâmetros físico-químicos da água dos aquários, isto é, o $\mathrm{pH}$, condutividade elétrica, oxigênio dissolvido, temperatura da manhã e da tarde, encontram-se na Tabela 2.

Os parâmetros físico-químicos da água dos aquários não apresentaram diferenças estatísticas $(\mathrm{P}<0,05)$ entre os tratamentos e permaneceram dentro dos limites para o bom desempenho da espécie, segundo Popma \& Phelps (1998).

Os valores médios das características de desempenho, obtidos ao final do experimento para peso final, ganho de peso, conversão alimentar e taxa de eficiência protéica estão apresentados na Tabela 3.

Observou-se uma redução linear $(\mathrm{P}<0,05)$ dos níveis de lipídeos nas rações sobre os valores de ganho de peso, o que está em desacordo com Chou \& Shiau (1996) para alevinos de tilápia híbrida ( $O$. niloticus x $O$. aureus), que determinaram um efeito quadrático do nível de inclusão de lipídeos na ração sobre o ganho de peso com o nível para o melhor desempenho de $12 \%$. Descordam dos dados apresentados por Stickney \& Wurtz (1986) que estudando o efeito da inclusão de níveis de lipídeos na ração $(0$, 2,5; 5,0; 7,5 e 10\%) de alevinos de tilápia azul (Tilapia aurea) onde determinaram os níveis de 7,5 e 10\% como o que proporcionam melhor desempenho. Por outro lado concordam com os dados de Hayashi et al. (1999b) que testando diferentes níveis de lipídeos para alevinos de carpa capim (Ctenopharyngodon idella) (3,0 a 10,0\% de gordura na ração) encontraram uma redução linear do desempenho à medida que se aumentavam os níveis de lipídeo na ração. Meer et al. (1997), em alevinos de tambaqui

Tabela 2 - Parâmetros físicos e químicos médios da água dos aquários dos diferentes tratamentos Table 2 - Average of chemical and physical parameters of aquarium waters in different treatments

\begin{tabular}{|c|c|c|c|c|c|c|c|}
\hline \multirow[t]{2}{*}{$\begin{array}{l}\text { Parâmetros } \\
\text { Parameters }\end{array}$} & \multicolumn{6}{|c|}{$\begin{array}{c}\text { Lipídeos na ração (\%) } \\
\text { Fat in diets }(\%)\end{array}$} & \multirow[t]{2}{*}{$\begin{array}{l}\mathrm{CV} \\
(\%)\end{array}$} \\
\hline & 3,00 & 4,80 & 6,60 & 8,40 & 10,20 & 12,00 & \\
\hline $\begin{array}{l}\text { Oxigênio dissolvido }(\mathrm{mg} / \mathrm{L}) \\
\text { Dissolved oxigen }(\mathrm{mg} / \mathrm{L})\end{array}$ & 3,85 & 4,17 & 3,96 & 3,56 & 3,82 & 3,56 & 27,32 \\
\hline $\begin{array}{l}\text { Condutiv. elétrica }(\mu \mathrm{S} / \mathrm{cm}) \\
\text { Eletric condut. }(\mu \mathrm{S} / \mathrm{cm})\end{array}$ & 0,32 & 0,31 & 0,32 & 0,33 & 0,31 & 0,33 & 9,16 \\
\hline $\begin{array}{l}\mathrm{pH} \\
\text { Temperatura - manhã }\left({ }^{0} \mathrm{C}\right)\end{array}$ & $\begin{array}{r}7,25 \\
26,73\end{array}$ & $\begin{array}{r}7,23 \\
26,65\end{array}$ & $\begin{array}{r}7,19 \\
26,62\end{array}$ & $\begin{array}{r}7,19 \\
26,79\end{array}$ & $\begin{array}{r}7,17 \\
26,79\end{array}$ & $\begin{array}{r}7,18 \\
26,59\end{array}$ & $\begin{array}{r}0,71 \\
0,52\end{array}$ \\
\hline $\begin{array}{l}\text { Morning temperature }\left({ }^{0} \mathrm{C}\right) \\
\text { Temperatura - } \operatorname{tarde}\left({ }^{0} \mathrm{C}\right) \\
\text { Evening temperature }\left({ }^{0} \mathrm{C}\right)\end{array}$ & 27,83 & 27,78 & 27,75 & 27,85 & 27,78 & 27,71 & 0,64 \\
\hline
\end{tabular}


Tabela 3 - Valores médios de desempenho de alevinos revertidos de tilápia do Nilo submetidos a diferentes níveis de lipídeos na ração

Table 3 - Average performance values of Nile Tilapia fingerlings fed diets with different fat levels

\begin{tabular}{|c|c|c|c|c|c|c|c|}
\hline \multirow[b]{2}{*}{$\begin{array}{l}\text { Característica } \\
\text { Characteristics }\end{array}$} & \multicolumn{6}{|c|}{$\begin{array}{l}\text { Lipídeos na ração (\%) } \\
\text { Fat in diets (\%) }\end{array}$} & \multirow[t]{2}{*}{$\begin{array}{l}\mathrm{CV} \\
(\%)\end{array}$} \\
\hline & 3,00 & 4,80 & 6,60 & 8,40 & 10,20 & 12,00 & \\
\hline $\begin{array}{l}\text { Peso inicial }(\mathrm{g}) \\
\text { Inicial weight }(\mathrm{g})\end{array}$ & 1,24 & 1,26 & 1,24 & 1,26 & 1,23 & 1,26 & 3,04 \\
\hline $\begin{array}{l}\text { Ganho de peso }(\mathrm{g})^{1} \\
\text { Weight gain }(g)^{1}\end{array}$ & 6,35 & 6,59 & 6,42 & 6,62 & 5,84 & 5,47 & 10,16 \\
\hline $\begin{array}{l}\text { Conversão alimentar } \\
\text { Food conversion }^{2}\end{array}$ & 1,69 & 1,69 & 1,66 & 1,66 & 1,80 & 1,90 & 8,16 \\
\hline $\begin{array}{l}\text { Taxa de eficiência protéica } \\
\text { Protein efficient ratio } \\
\text { Plo }\end{array}$ & 1,85 & 1,85 & 1,88 & 1,88 & 1,74 & 1,66 & 7,01 \\
\hline
\end{tabular}

${ }^{1}$ Efeito linear $Y=6,98608-0,207954 X, r^{2}=0,56$

2 Efeito linear $Y=1,57109+0,00222195 X, r^{2}=0,60$.

3 Efeito linear $Y=1,9613-0,0021615 X, r^{2}=0,59$.

Linear effect $Y=6,98608-0,207954 X, r^{2}=.56$.

Linear effect $Y=1,57109+0,00222195 X, r^{2}=.60$

Linear effect $Y=1,9613-0,0021615 X, r^{2}=.59$.

(Colossoma macropomum), não encontraram influência do nível de lipídeos da ração sobre o desempenho dos mesmos, o que está em desacordo com os dados apresentados.

A ração com 3,0\% de lipídeos fornece cerca de três vezes mais que a exigência da espécie em ácidos graxos essenciais (NRC, 1993). Níveis mais altos de lipídeos diminuíram o desempenho dos alevinos; observou-se que à medida que o lipídeo aumenta, diminui-se a quantidade de amido presente nas rações, pois o milho é substituído pelo óleo de soja, o que demonstra que a tilápia do Nilo utiliza bem o carboidrato da ração, fato este em consonância com os resultados de Viola \& Arieli (1983), Anderson et al. (1984), Degani \& Revach (1991) e Shiau (1997). Os lipídeos atuam como fonte de ácidos graxos essenciais e influencia pouco no fornecimento de energia para o crescimento dos mesmos, concordando com afirmações de Lovell (1989), El-Dahhar \& El-Shazly (1993)e Chou \& Shiau (1996).

A conversão alimentar também apresentou redução linear em relação ao aumento dos níveis de lipídeos na ração. Estes dados se assemelham aos de Meer et al. (1997), que observaram melhora deste parâmetro nas rações com 5 e $10 \%$ em relação às de 15 e $20 \%$ de lipídeo para tambaqui, porém divergem dos resultados obtidos por Chou \& Shiau (1996), que não observaram efeito do nível de gordura na ração sobre a conversão alimentar em alevinos de tilapia híbrida. Os dados diferem também dos determinados por Stickney \& Wurtz
(1986), que não notaram diferença na conversão alimentar de alevinos de tilápia azul nos níveis de 5 , 7,5 e $10 \%$ de inclusão de lipídeo na ração.

A redução linear apresentada pelos níveis de lipídeos na ração sobre a conversão alimentar demonstra que altos níveis de lipídeos diminuem o aproveitamento do alimento por esta espécie, o que implica em uma maior excreção de material fecal para o meio, com conseqüente aumento da carga poluente do meio.

A taxa de eficiência protéica também apresentou redução linear, à medida que se elevou o nível de lipídeo na ração, o que demonstra que o efeito do lipídeo da ração em desviar a proteína da dieta da produção de energia para o anabolismo corporal, evidenciado em salmonídeos (Lovell, 1989), não ocorre nesta espécie. Ocorre justamente o inverso, passando o carboidrato, no caso o amido do milho e do farelo de soja, a exercer tal efeito.

Os valores médios para a velocidade de trânsito do alimento, consumo de ração e gordura corporal encontram-se na Tabela 4.

A porcentagem de gordura corporal apresentou aumento linear em função do aumento do nível de lipídeo na ração, resultado semelhante aos obtidos por Pezzato et al. (1992) para alevinos de pacu (Piaractus mesopotamicus); Gatlin III \& Bai (1993) para o bagre do canal (Ictalurus punctatus); Chou \& Shiau (1996) para híbridos de tilápia; Meer et al (1997) com tambaqui e concorda com Cyrino (1995). 
Tabela 4 - Valores médios para velocidade de trânsito do alimento, gordura corporal e consumo de ração Table 4 - Food speed transit, body fat and feed intake averages

\begin{tabular}{lccccccc}
\hline & \multicolumn{5}{c}{$\begin{array}{c}\text { Lipídeos na ração (\%) } \\
\text { Fat in diets (\%) }\end{array}$} & $\begin{array}{c}\text { CV } \\
(\%)\end{array}$ \\
\cline { 2 - 7 } $\begin{array}{l}\text { Característica } \\
\text { Characteristics }\end{array}$ & 3,00 & 4,80 & 6,60 & 8,40 & 10,20 & 12,00 & \\
\hline $\begin{array}{l}\text { Velocidade de trânsito (h) } \\
\text { Transit velocity (h) }\end{array}$ & 1,56 & 1,56 & 1,62 & 1,44 & 1,50 & 1,94 & 37,74 \\
$\begin{array}{l}\text { Consumo de ração (\%)* } \\
\begin{array}{l}\text { Food intake (\%)* } \\
\text { Gordura corporal (\%) } \\
\text { Body fat (\%) }\end{array}\end{array}$ & 1,33 & 1,10 & 1,54 & 1,54 & 1,44 & 1,10 & 36,74 \\
\hline
\end{tabular}

${ }^{1}$ Efeito quadrático $(P<0,05) Y=3,65052-0,12213 X+0,01009 X^{2}, r^{2}=0,12$.

2 Efeito linear $(P<0,05) Y=3,23000+0,51329 X, r^{2}=0,79$

* Consumo alimentar em relação ao peso vivo dos animais da unidade experimental.

${ }_{1}^{1}$ Quadratic effect $(P<.05) Y=3,65052-0.12213 X+0.01009 X^{2}, r^{2}=.12$.

2 Linear effect $(P<.05) Y=3.23000+0.51329 X, r^{2}=.79$

${ }^{*}$ Food intake in relation to experimental unit animal weight.

Uma prova marcante do baixo aproveitamento de lipídeos como fonte de energia por alevinos de tilápia é o efeito observado de que o aumento de lipídeos na ração além de influenciar negativamente o desempenho, acaba sendo depositado como gordura corporal, fato este que está de acordo com Chou \& Shiau (1996) que afirmam também que as tilápias não usam a energia da lipídeos suplementar da ração, acima de $5 \%$, para o crescimento. $O$ excesso de gordura na carcaça é, atualmente, uma característica indesejável, devendo manter-se em um nível que não afete as características organolépticas da carne e auxilie na manutenção da qualidade desta durante o período de congelamento. Outro fator negativo do excesso de gordura na carcaça é que esta acumula-se principalmente no tecido adiposo da cavidade abdominal, o que diminui a percentagem de rendimento de filé e consequentemente o valor comercial do peixe.

Os níveis de lipídeos na ração não afetaram o consumo alimentar (Tabela 3), indicando que o aumento da inclusão de óleo de soja na ração não influenciou na aceitabilidade da ração, demonstrando que o nível de lipídeos na ração peletizada, quando se utiliza o óleo de soja como fonte, não tem efeito atrativo, nem inibidor do consumo de ração.

Observou-se um efeito quadrático $(\mathrm{P}<0,05)$ (Tabela 3) na velocidade de trânsito do alimento em função dos níveis de lipídeos na ração, apresentando o menor valor na velocidade de trânsito ao nível de inclusão de 6,0\% de gordura na ração, Zimmermann \& Jost (1998) citam que dietas ricas em lipídeos são retidas no estômago por um período de tempo mais longo, pelo estimulo da produção da colecistoquinina que reduz a motilidade gástrica. A velocidade de trânsito do alimento pelo trato digestivo do animal, é responsável pelo tempo que alimento fica exposto aos processos digestivos e absortivos do organismo, influenciando a eficiência de absorção dos mesmos (Zanotto et al., 1995; NRC, 1993). Shiau (1997) afirma que a absorção dos nutrientes depende do tempo em que os nutrientes estão em contato com o epitélio de absorção; dessa forma e de acordo com Zimmermann \& Jost (1998), uma dieta que tem uma alta velocidade de passagem pelo trato digestivo pode resultar em baixo aproveitamento do alimento, pois o mesmo permanece tempo insuficiente no trato digestivo para sofrer o processo de digestão e absorção. Por outro lado, tempo excessivo de permanência do alimento no trato digestivo levaria a um menor desempenho do animal, pelo fato de ele ocupar o espaço que poderia estar sendo ocupado por um novo alimento.

Relacionando a gordura corporal com as curvas de ganho de peso, taxa de eficiência protéica e conversão alimentar apresentadas pode-se inferir que a partir de 3\% de lipídeos na ração, os lipídeos não são aproveitados para o crescimento corporal e sim armazenados como tecido adiposo em detrimento do desempenho do alevino. Isto pode estar relacionado com a diminuição do carboidrato da ração, à medida que os lipídeos aumentam e este desbalanceamento lipídeo/carboidrato pode, então, forçar o metabolismo 
do peixe a utilizar aminoácidos glicogênicos para a manutenção da glicose sangüínea, já que a gordura não entra em nenhum momento na via gliconeogênica. Esta possível utilização de aminoácidos como fonte de glicose implica na desaminação dos mesmos e conseqüente excreção desta amônia, o que mesmo não sendo tão onerosa, quanto ao gasto de energia, em relação a animais ureotélicos e urotélicos; implica em um gasto adicional de energia quando comparado a utilização do próprio amido como fonte de glicose (Lehninger et al. 1995), além do que a amônia é extremamente tóxica aos peixes (Wood, 1993). Entretanto, estas inferências são apenas teóricas, sendo necessária uma investigação mais apurada no metabolismo do animal para a comprovação ou não destes fatos.

\section{Conclusões}

Para alevinos de tilápia do Nilo revertidos, o aumento do nível de lipídeos da ração tem efeito quadrático sobre a velocidade de trânsito do alimento, leva à redução linear no desempenho e aumento linear na porcentagem de gordura corporal. Concluiu-se que os lipídeos não são boa fonte de energia para o crescimento, entretanto, o amido é bem aproveitado para tal fim; recomenda-se um nível de 3,0\% de lipídeos na ração para tilápia do Nilo nesta fase de desenvolvimento.

\section{Literatura Citada}

ANDERSON, J.; JACKSON, A.J.; MATTY, A.J. et al. Effects of dietary carbohydrats and fibre on the tilapia, Oreochromis niloticus (Linn.). Aquaculture, v.13, p.265-272, 1984.

CHOU, B.S.; SHIAU, S.Y. Optimal dietary lipid level for growth of juvenile hybrid tilapia, Oreochromis niloticus x Oreochromis aureus. Aquaculture, v.143, n.2, p.185-195, 1996.

CYRINO, J.E.P. Regulação nutricional do alimento. In: SIMPÓSIO INTERNACIONAL SOBRE NUTRIÇÃO DE PEIXE E CRUSTÁCEOS, 1., 1995, Campos do Jordão. Anais... Campos do Jordão: Conselho Brasileiro de Nutrição Animal, 1995. p.69-91.

DEGANI, G.; REVACH, A. Digestive capabilities of three commensal fish species: carp, Cyprinus carpio L., tilapia, Oreochromis aureus X O. niloticus, and African catfish, Clarias gariepinus (Burchel 1822). Aquaculture and Fisheries Management, v.22, p.397-403. 1991.

EL-DAHHAR, A.A.; EL-SHAZLY, K. Effect of essential amino acids (methionine and lysine) and treated oil in fish diet on growth performance and feed utilization of Nile tilapia, Tilapia nilotica (L.). Aquaculture and Fishieries Management, v.24, n.6, p.731-739, 1993.

EUCLYDES, R.F. Manual de utilização do programa SAEG (Sistema para Análises Estatísticas e Genéticas). Viçosa, Universidade Federal de Viçosa, 1983. 59p.
GATLIN III, D.M.; BAI, S.C. Effects of dietary lipid and reduced glutathione on composition and storage quality of channel catfish, Ictalurus punctatus (Rafinesque). Aquaculture and Fishieries Management, v.24, n.4, p.457463, 1993.

HAYASHI, C.; BOSCOLO, W. R.; SOARES, C. M. et al. Uso de diferentes graus de moagem dos ingredientes em dietas para tilápia do Nilo (Oreochromis niloticus L.) na fase de crescimento. Acta Scientiarum, v.21, n.3, p.733-737, 1999a.

HAYASHI, C.; MEURER, F.; SOARES, C.M. et al. Utilização de diferentes níveis de gordura em dietas para alevinos de carpa-capim (Ctenonpharyngodon idella, V). In: CONGRESSO BRASILEIRO DE ENGENHARIA DE PESCA, 11, 1999, Olinda. Anais... Olinda: Congresso Brasileiro de Engenharia de Pesca: 1999b. p.201-210.

HAYASHI, C.; SOARES, C.M.; MEURER, F. et al. Uso de diferentes óleos vegetais em dietas para a tilápia do Nilo (Oreochromis niloticus, L.), na fase inicial. In: REUNIÃO DA SOCIEDADE BRASILEIRA DE ZOOTECNIA, 37., 2000, Viçosa. Anais... Viçosa: Sociedade Brasileira de Zootecnia, 2000. CD ROM

JAUNCEY, K.; ROSS, B. A guide to tilapia feeds and feeding. Institute of Aquaculture. University of Stirling: Stirling. 1982. $111 \mathrm{p}$.

LEHNINGER, A.L.; NELSON, D.L.; COX, M.M. Princípios de bioquímica. Savier: São Paulo, 1995.

LOVELL, R.T. Nutrition and feeding of fish. New York: Van Nostrand Reinhold, 1989. 260p.

MEER, M.B.; ZAMORA, J.E.; VERDEGEM, M.C.J. Effect of dietary lipid level on protein utilization and the size and proximate composition of body compartments of Colossoma macropomum (Cuvier). Aquaculture Research, v.28, n.6, p.405-417, 1997.

NATIONAL RESEARCH COUNCIL - NRC. Nutrient requirements of fish. Washington, D.C.: National Washington Academy Press, 1993. 114p.

PEZZATO, L.E.; CASTAGNOLLI, N.; BARROS, M.M. et al. Efeito de diferentes níveis de gordura de origem animal e vegetal, sobre o depósito de ácidos graxos em pacú (Piaractus mesopotamicus). In: SIMPÓSIO BRASILEIRO DE AQUICULTURA, 7., ENCONTRO BRASILEIRO DE PATOLOGIA DE ORGANISMOS AQUÁTICOS, 2., 1992, Peruíbe. Anais... Peruíbe: Simpósio Brasileiro de Aquicultura, 1992. p.104-111.

PEZZATO, L.E. Alimentos convencionais e não-convencionais disponíveis para indústria da nutrição de peixes no Brasil. In: SIMPÓSIO INTERNACIONAL SOBRE NUTRIÇÃO DE PEIXE E CRUSTÁCEOS, 1., 1995, Campos do Jordão. Anais... Campos do Jordão: Conselho Brasileiro de Nutrição Animal, 1995. p.34-52.

POPMA, T.J.; PHELPS, R.P. Status Report to Commercial Tilápia Producers on Monosex Fingerling Production Techniques. In: AQUICULTURA BRASIL'98, 1., 1998, Recife. Anais... Recife: Simpósio Brasileiro de Aquicultura, 1998. p.127-145.

ROSTAGNO, H.S.; ALBINO, L.F.T.; DONZELE, J.L. et al. Tabelas brasileiras para aves e suínos - Composição de alimentos e exigências nutricionais. Viçosa, MG: Universidade Federal de Viçosa, 2000. 141p.

ROSTAGNO, H.S.; SILVA, D.J.; COSTA, P.M.A. et al. Composição de alimentos e exigências e nutricionais de aves e suínos (Tabelas brasileiras). Viçosa, MG: Universidade Federal de Viçosa, 1994. 61p. 
SHIAU, S.Y. Utilization of carbohydrates in warmwater fish with particular reference to tilapia, Oreochromis niloticus $\mathrm{x}$ O. aureus. Aquaculture, v.151, p.79-96, 1997.

SILVA, D.J. Análise de alimentos (Método químicos e biológicos). Viçosa, MG: Universidade Federal de Viçosa, 1990. 165 p.

SINTAYEHU, A.; MATHIES, E.; MEYER-BURFDORF, K.H. Apparent digestibilities and growth experiment with tilapia (Oreochromis niloticus) fed soybean meal, cottonseed meal and sunflower seed meal. Journal of Applied Ichthyology, v.12, n.2, p.125-130, 1996

STEFFENS, W. Princípios fundamentales de la alimentación de los peces. Madri: Acribia, 1987. 275p.

STICKNEY, R.R.; McGEACHIN, R.B. Effects of dietary lipid quality on growth and food convertion of tilápia. Proc. Annu. Conf. Southeast. Association Fish and Wildlife Agencies, v.37, p.352-357, 1983.

STICKNEY, R.R.; WURTZ, W.A. Growth response of blue tilapias to selected levels of dietary menhaden and catfish oils. The Progressive Fish-Culturist, v.48, p.107-109, 1986.

VIOLA, S.; ARIELI, Y. Evaluation of different grains as ingredients in complete feeds for carp and tilapia in intensive culture. Israeli Journal of Aquaculture, v.35, p.38-43, 1983.

WILSON, R.P. Lipid nutrition of finfish. Nutrition and utilization technology. In: LIM, C; SESSA, D.J. (Eds.) Nutrition and utilization technology in aquaculture. Champaign: AOAC Press, 1995. p.74-81.
WILSON, R.P. State of art of warmwater fish nutrition. In: AQUICULTURA BRASIL'98, 1., 1998, Recife. Anais... Recife: SIMBRAQ, 1998. p.375-380.

WOOD, C.M. Ammonia and urea metabolism and excretion. The physiology of fishes. CRC Press, 1993. p.379-426.

ZANOTTO, D.L.; NICOLAIEWSKY, S.; FERREIRA, A.S. et al. Granulometria do milho na digestibilidade das dietas para suínos em crescimento e terminação. Revista Brasileira de Zootecnia, v.24, n.6, p.428-436, 1995.

ZIMMERMANN, S.; JOST, H.C. Recentes avanços na nutrição de peixes: a nutrição por fases em piscicultura Intensiva. In: SIMPÓSIO SOBRE MANEJO E NUTRIÇÃO DE PEIXES, 1., 1998, Piracicaba. Anais... Piracicaba: Conselho Brasileiro de Nutrição Animal, 1998. p.123-162.

Recebido em: 26/09/00

Aceito em: 05/11/01 